EGU21-11067, updated on 04 Mar 2021

EGU General Assembly 2021

(c) Author(s) 2021. This work is distributed under

the Creative Commons Attribution 4.0 License.

\title{
Landslides, river incision and environmental change: the Ruzizi gorge in the Kivu Rift
}

Toussaint Mugaruka Bibentyo ${ }^{1,2,3}$, Antoine Dille ${ }^{1,4}$, Arthur Depicker ${ }^{5}$, Benoît Smets ${ }^{1,4}$, Matthias Vanmaercke $^{6}$, Charles Nzolang ${ }^{3}$, Stijn Dewaele ${ }^{2}$, and Olivier Dewitte ${ }^{1}$

${ }^{1}$ Department of Earth Sciences, Royal Museum for Central Africa, Tervuren, Belgium (toussaintbib@gmail.com)

${ }^{2}$ Department of Geology, Ghent University, Ghent, Belgium (toussaint.mugarukabibentyo@ugent.be)

${ }^{3}$ Département de Géologie, Université Officielle de Bukavu, Bukavu, DR Congo

${ }^{4}$ Department of Geography, Earth System Science, Vrije Universiteit Brussel, Brussels, Belgium

${ }^{5}$ Department of Earth and Environmental Sciences, KU Leuven, Leuven, Belgium

${ }^{6}$ Department of Geography, University of Liège, Liège, Belgium

The understanding of the interplay between natural and human induced factors in the occurrence of landslides remains poorly constrained in many regions, especially in tropical Africa where datascarcity is high. In these regions where population growth is significant and causes changes in land use/cover, the need for a sustainable management of the land is on the rise. Here, we aim to unravel the occurrence of landslides in the $40 \mathrm{~km}$-long Ruzizi gorge, a rapidly incising bedrock river in the Kivu Rift in Africa that has seen its landscape disturbed over the last decades by the development of the city of Bukavu (DR Congo). Careful field observations, historical aerial photographs, satellite imagery and archive analysis are combined to produce a multi-temporal inventory of 264 landslides. We show that the lithological context of the gorge and its extremely high incision rate $\left(>20 \mathrm{~mm}_{\text {year }}{ }^{-1}\right)$ during the Holocene explains the presence of a concentration of large landslides (up to $2 \mathrm{~km}^{2}$ ) of undetermined age (well before the first observations of 1959) whose occurrence is purely natural. They are mostly of the slide type and do not show morphologic patterns of recent activity. The landslides that occurred during the last 60 years are flow-like shallower slope failures of smaller size (up to $0.12 \mathrm{~km}^{2}$ ) and tend to disappear rather quickly (sometimes within a few years) from the landscape as a result of rapid vegetation growth, land reclamation and (human-induced) soil erosion. They are primarily related to threshold slopes and precipitation plays a frequent role in their onset. However, land use/cover changes also affect their occurrence. This study provides useful information for a more accurate evaluation of the landslide hazard in the area, particularly with respect to the growth of the city of Bukavu that has developed without the consideration of naturally instable slopes. It also stresses the need and added value of building accurate landslide inventories in data-scarce regions. 